\title{
A retrospective study on findings of canine hip dysplasia screening in Kenya
}

\author{
Peter Kimeli ${ }^{1}$, Susan W. Mbugua ${ }^{1}$, Roger M. Cap ${ }^{2}$, Gilbert Kirui ${ }^{1}$, Tequiero O. Abuom ${ }^{1}$, Willy E. Mwangi ${ }^{1}$,
} Ambrose N. Kipyegon ${ }^{1}$ and John D. Mande ${ }^{1}$

\begin{abstract}
1. Department of Clinical Studies, Faculty of Veterinary Medicine, University of Nairobi, P.O. Box 29053-00625, Kangemi, Kenya; 2. Sercombe Veterinary Surgeons, P.O Box 24878-00502, Nairobi, Kenya.

Corresponding author: Peter Kimeli, e-mail: kimeli08@yahoo.com, SWM: swmbugua80@gmail.com,

RMC: roger.cap.rc@gmail.com,GK: kgkirui@gmail.com, TOA: toabuom@uonbi.ac.ke, WEM: drwillymwangi@yahoo.com, ANK: kipyegongeno@yahoo.com, JDM: jdemesi@gmail.com
\end{abstract}

Received: 15-06-2015, Revised: 27-09-2015, Accepted: 14-10-2015, Published online: 22-11-2015

doi: 10.14202/vetworld.2015.1326-1330 How to cite this article: Kimeli P, Mbugua SW, Cap RM, Kirui G, Abuom TO, Mwangi WE, Kipyegon AN, Mande JD (2015) A retrospective study on findings of canine hip dysplasia screening in Kenya, Veterinary World 8(11): 1326-1330.

\begin{abstract}
Aim: The current study was undertaken to evaluate the findings of canine hip dysplasia screening in Kenya.

Materials and Methods: Records for $591 \mathrm{dogs}$ were included in this study. The data was obtained from the national screening office, Kenya Veterinary Board, for the period between the years 1998 and 2014. Monthly screening records were assessed and information relating to year of evaluation, breed, sex, age, and hip score captured. Descriptive statistics of hip scores was computed based on year, sex, age, and breed.
\end{abstract}

Results: A total of 591 records from the year 1998 to 2014 were retrieved at the National Screening Centre, the Kenya Veterinary Board. Each record was examined and data pertaining to year of screening, the breed, sex, age of the dogs, and the total hip score were recorded. The highest number of dogs screened for hip dysplasia (HD) was in the year 2009 and the lowest in the year 1998. More females than males were screened for HD and the mean age of all the dogs was $22.9 \pm 12.7$ months. The most common breeds of dogs screened during the study period were German Shepherd (67.0\%), Rottweiler (15.6\%), and Labrador Retriever (12.2\%). The mean hip score for the 591 dogs was $15.1 \pm 10.9$ and the median 12.0. The mean hip scores per breed were; German Shepherd (16.3 \pm 12.1$)$; Golden Retriever (16.0); Hungarian Vizla (15.0);

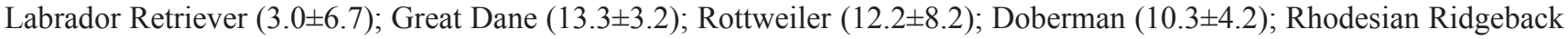
(9.6 \pm 3.8$)$; and Boxer (9.3 \pm 0.6$)$. Based on the hip score, moderate to severe HD was diagnosed in $16.6 \%$ of the dogs, mild HD in $32.7 \%$, Borderline HD in $37.7 \%$, fair HD in $6.9 \%$, and good HD in $6.1 \%$.

Conclusion: Canine HD is a common occurrence in Kenya with most dogs suffering mild to border line HD. In addition, German Shepherd and Golden Retriever appear to be the most affected breeds. It is therefore recommended that stringent measures be imposed to dog breeding programs to avoid transmission of this undesirable trait and consequently improve the welfare and the quality of dog breeds in Kenya.

Keywords: dogs, hip dysplasia, hip score, Kenya.

\section{Introduction}

Hip dysplasia (HD) is a common and potentially debilitating orthopedic disease in dogs [1] characterized by laxity of the coxofemoral joint leading to secondary osteoarthritis, pain, and reduction in joint function [2]. The condition is manifested by decreased congruence between femoral head and acetabulum resulting in degenerative damage to the joint $[3,4]$. Although the etiology of this condition is not fully understood, environmental influences such as obesity, injury at a young age, overexertion on hip joint or round ligament tear at a young age, repetitive motion on forming coxofemoral joint, and excess dietary calcium/vitamin D are said to play key roles. HD primarily affects medium-sized and large-breed of dogs and has high heritability of up to $95 \%$ [5-8].

Radiographic techniques have been developed and are widely used to identify dogs which are less

Copyright: The authors. This article is an open access article licensed under the terms of the Creative Commons Attributin License (http:// creative commons.org/licenses/by/2.0) which permits unrestricted use, distribution and reproduction in any medium, provided the work is properly cited. affected by the disease for purposes of breeding [9]. Internationally, three scoring modes are widely in use: The Fédération Cynologique Internationale, the Orthopedic Foundation for Animals (OFA), and the British Veterinary Association/The Kennel Club (BVA/KC) [6].

The Kenya Veterinary Board (KVB) is the officially mandated institution that conducts canine HD screening in Kenya on behalf of the East Africa KC (EAKC). This institution has been screening dogs for $\mathrm{HD}$ using the BVA/KC system and advocating for breeding of dogs with good hips since 1998 (Personal communication).

The BVA/KC system scores hip joints based on the severity of changes of nine specific morphological radiographic criteria which include Norberg angle; subluxation; cranial acetabular edge; dorsal acetabular edge; cranial effective acetabular rim; acetabular fossa; caudal acetabular edge; femoral head and neck exostoses, and femoral head recontouring [2].

Information on canine hip score findings has not been documented in Kenya. This study was therefore conducted to determine the occurrence of HD and the 
prevailing scores among canines presented to KVB for hip scoring in the period between 1998 and 2014.

\section{Materials and Methods \\ Ethical approval}

This was a retrospective study, and no animal was used. The information was recovered from routinely kept records in the national canine hip screening office, with their permission.

\section{Source of data}

The study included all hip-dysplasia screening records for 591 dogs of different breeds from various breeders across the country. The data was obtained from the national screening office, KVB, for the period between the years 1998 and 2014.

\section{HD screening}

Routinely, all the official hip radiographs are judged by a minimum of two trained and experienced veterinary surgeons appointed by the KVB. The panelists are drawn from both the university and private veterinary hospitals. As a requirement, all the radiographs must bear the dogs' microchip or tattoo number, which is the registration number of the EAKC, and this is cross-checked with the details on the application form. In addition, radiographs must satisfy the set criteria for accurate scoring and interpretation of hips in dogs.

\section{Data management}

Using monthly screening records, all relevant data that included year of evaluation, breed, sex, age, and hip score was captured. The data from the archived records was entered and stored in Microsoft office excel 2007 (Microsoft Corporation, 2007) and exported to statistical analytical system (SAS) 20022003 (SAS Institute, Inc., Cary, NC, USA) for analysis. Descriptive statistics of hip scores was computed based on year, sex, age, and breed. Grading of hip scores was done based on $\mathrm{BVA} / \mathrm{KC}$ as described by Flückiger et al. [6].

\section{Results}

\section{General demographics}

A total of 591 hip score records were examined in this study. Generally, the number of dogs screened for HD increased exponentially from 1998 through to 2014 as shown in Table-1. A similar trend was also observed in the breeds of dogs.

More female $(67.5 \%)$ than male $(32.5 \%)$ dogs were screened for HD. This finding was consistent for all the years of study.

German Shepherds (67.0\%) were the most common breed screened for HD during the study period followed by Rottweilers (15.6\%) and Labrador Retrievers (12.2\%). The least common breeds were Golden Retrievers (0.2\%) and Hungarian Vizlas $(0.2 \%)$.

Dogs screened for HD were aged between 12

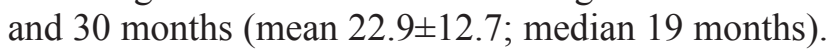

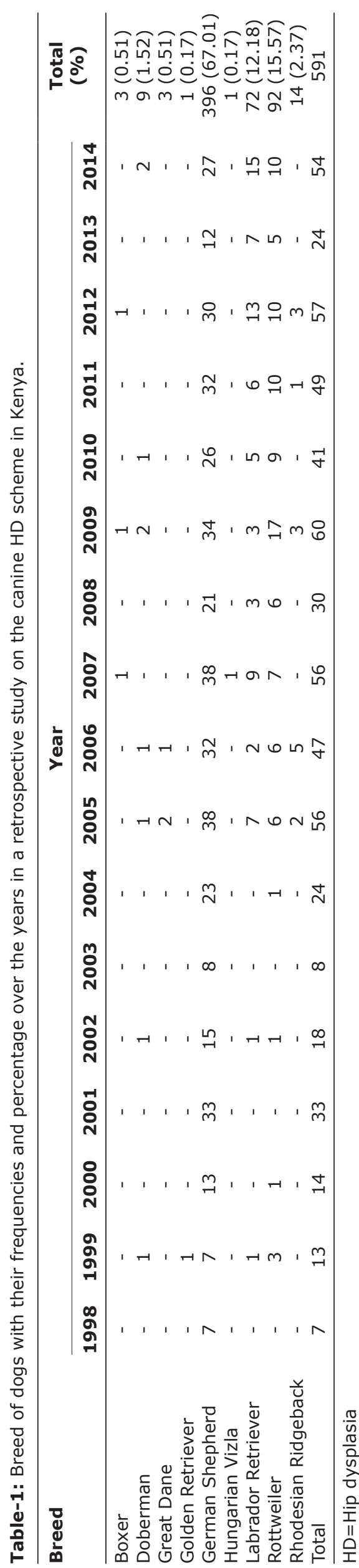

Veterinary World, EISSN: 2231-0916 
The greatest number of screened dogs was in the age range of $12-24$ months $(70.7 \% ; 418 / 591)$, followed by $25-48$ months $(24.2 \%$; $143 / 591)$ and more than 48 months $(5.1 \%$; 30/591).

\section{Hip scores}

The mean hip score for the 591 dogs screened during the study period was $15.1 \pm 10.9$ (median 12.0). The mean hip score for female dogs $(16.2 \pm 11.6$; median 13.0) was higher than that of males (12.8 \pm 8.9 ; median 11.0). Highest mean hip score was in German Shepherds (Mean 16.3 \pm 12.1 ; Median 13.0) whereas the lowest mean score was observed in Boxer (Mean 9.3 \pm 0.6 ; Median 9.0) as shown in Table-2. The mean hip score remained fairly constant over the years (Figure-1).

Dogs aged between 12 and 24 months recorded a mean hip score of $15.3(n=418$; median 12.0$)$ whereas those aged 25-48 months and more than 48 months had mean hip score of $14.7(\mathrm{n}=143$; median 13.0) and $14.4(\mathrm{n}=30$; median 13.0), respectively.

Moderate to severe HD (hip score $>18$ ) was diagnosed in $16.6 \%$ of dogs. On the other hand, mild HD (hip score $13-18$ ) affected $32.7 \%$ of dogs, borderline HD (hip score 9-12) 37.7\%, fair HD (hip score 7-8) $6.9 \%$, and good HD (hip score 1-6) $6.1 \%$ of dogs (Tables-3 and 4).

\section{Discussion}

The results of this study indicate that the number of dogs submitted by breeders and dog owners for HD screening has been increasing over the years. This trend could be attributed to the growing interest in dog breeding in response to the available market especially for security dogs and pets.

The three most predominant dog breeds were German Shepherds, Rottweilers, and Labrador Retrievers. This breed distribution was partly in agreement with previous study [10]. The German Shepherd breed, which is primarily a working dog, is widely known and used in the national security forces, private security companies, and homesteads. It is believed to be the most bred dog in the country. The German Shepherd breed mean score was higher than that of the total mean score in all dogs considered in this study suggesting that they are more predisposed to HD.

The prevalence and severity of canine HD were most likely related to the breed's predisposition to the disease and the previous absence of a radiographic HD control program [11]. In many countries in the world, good results were achieved in the reduction of the HD frequency through controlled breeding of various dog breeds [12].

Regarding German Shepherd, the prevalence of HD was $19.44 \%$ (77/396). This percentage was lower than that reported by the OFA preliminary hip data $(32.9 \%)$ and that reported by one study [10] which was $36.14 \%$. Regarding Rottweiler, HD was recorded in $10.86 \%(10 / 99)$ of the screened dogs which was also lower than that reported by one study [10] which was $30.78 \%$ and OFA database $(20.2 \%)$. In Labrador Retriever, HD was positive in $13.89 \%$ $(10 / 72)$ of the cases which was also considered lower than that reported which was $27.23 \%$ [10] and slightly higher than that recorded by OFA database $(11.7 \%)$. These differences could be attributed to the varied management practices in the different countries.

Most of the radiographs, which were brought for scoring, belonged to dogs that were between the

Table-2: HD score descriptions in different dog breeds and sexes in a retrospective study on the canine hip dysplasia scheme in Kenya.

\begin{tabular}{|c|c|c|c|c|}
\hline Breed & Sex & Mean & Median & $\begin{array}{l}\text { Standard } \\
\text { deviation }\end{array}$ \\
\hline \multirow[t]{3}{*}{ Boxer } & $\mathrm{F}$ & 9.0 & 9.0 & 0.0 \\
\hline & $M$ & 10.0 & 10.0 & - \\
\hline & All & 9.3 & 9.0 & 0.6 \\
\hline \multirow[t]{3}{*}{ Doberman } & $\mathrm{F}$ & 10.6 & 10.0 & 4.8 \\
\hline & $M$ & 9.5 & 9.5 & 2.1 \\
\hline & All & 10.3 & 10.0 & 4.2 \\
\hline \multirow[t]{3}{*}{ Great Dane } & $\mathrm{F}$ & 17.0 & 17.0 & - \\
\hline & $M$ & 11.5 & 11.5 & 0.7 \\
\hline & All & 13.3 & 12.0 & 3.2 \\
\hline \multirow[t]{3}{*}{ Golden Retriever } & $\mathrm{F}$ & 16.0 & 16.0 & \\
\hline & $M$ & - & - & - \\
\hline & All & 16.0 & 16.0 & - \\
\hline \multirow[t]{3}{*}{ German Shepherd } & $\mathrm{F}$ & 17.5 & 14.0 & 12.8 \\
\hline & $M$ & 13.6 & 11.0 & 10.2 \\
\hline & All & 16.3 & 13.0 & 12.1 \\
\hline \multirow[t]{3}{*}{ Hungarian Vizla } & $\mathrm{F}$ & - & - & - \\
\hline & M & 15.0 & 15.0 & - \\
\hline & All & 15.0 & 15.0 & - \\
\hline \multirow[t]{3}{*}{ Labrador Retriever } & $\mathrm{F}$ & 15.2 & 13.0 & 7.3 \\
\hline & $M$ & 11.7 & 12.0 & 3.9 \\
\hline & All & 14.3 & 12.5 & 6.7 \\
\hline \multirow[t]{3}{*}{ Rottweiler } & $\mathrm{F}$ & 12.7 & 11.0 & 9.1 \\
\hline & $M$ & 11.3 & 9.0 & 6.4 \\
\hline & All & 12.2 & 10.0 & 8.2 \\
\hline \multirow[t]{3}{*}{ Rhodesian Ridgeback } & $\mathrm{F}$ & 10.1 & 10.5 & 3.1 \\
\hline & M & 9.0 & 7.5 & 4.8 \\
\hline & All & 9.6 & 10.0 & 3.8 \\
\hline \multirow[t]{3}{*}{ All } & $\mathrm{F}$ & 16.2 & 13.0 & 11.6 \\
\hline & $M$ & 12.8 & 11.0 & 8.9 \\
\hline & All & 15.1 & 12.0 & 10.9 \\
\hline
\end{tabular}

$\mathrm{HD}=$ Hip dysplasia

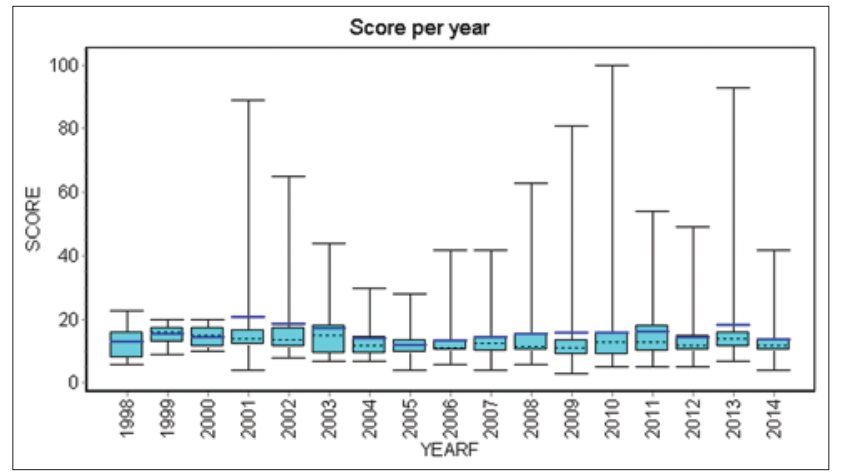

Figure-1: Plot showing the trend of mean hip score over the years. 


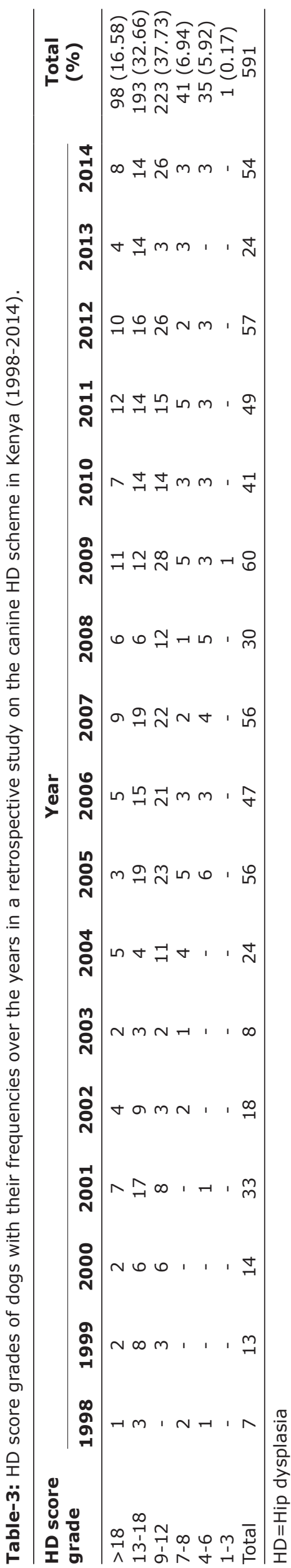

ages of 12-24 months. This is a positive sign because the earlier poor hips are detected the better as they are eliminated from the breeding program. Moreover, therapeutic intervention may be done, if the dog is used for companionship.

The study also revealed that there were more females than males. The females also had a higher average hip score, which may be due to the fact that more females were kept in breeding kennels than males due to the whelping advantage. Moreover, one male was enough to service several females therefore bringing out the economic advantage. The tendency of females to have higher hip scores than males is probably an incidental finding simply due to the fact that more than $67 \%$ of the canine population considered in this study were actually females.

Two approaches of canine HD management has been described, which include conservative management and surgery [13]. Conservative management has been achieved by a combination of exercise restriction, weight control, analgesics, and physical therapies $[14,15]$. Surgery aims to prevent/limit the development of HD or reduce/eliminate pain through salvage. Surgical techniques that have been used with success include juvenile pubic symphysiodesis [13], pelvic osteotomy [16,17], pelvic ostectomy [18], denervation of hip joint capsule [13], shelf arthroplasty $[19,20]$, intertrochanteric femoral osteotomy, excision arthroplasty, and total hip replacement [13]. However, the most effective way to reducing incidences of canine HD has been screening the defect and breeding against it $[21,22]$.

Canine HD is a complex polygenic disease due to the small additive effect of many genes $[23,24]$. Environmental factors such as sex, age, and body weight have been reported to influence the expression and severity of the disease $[25,26]$. In addition, diet has been shown to have a significant effect on the development of HD in dogs predisposed to the disease and on the prevalence, severity, and clinical signs of osteoarthritis $[10,13,27]$.

It is concluded that canine HD is present in Kenyan dogs and that the dog owners, breeders, and the Kennel Club have adopted and continue to implement the selection program of dog breeds free from $\mathrm{HD}$ on the basis of a devised hip scoring scheme. This helps to further decrease the frequency of HD.

\section{Authors' Contributions}

The data was collected by PK, SWM, and RMC. Statistical analysis was performed by GK, TOA, WEM, ANK, and JDM. Manuscript was drafted and revised by PK. All authors read and approved the final manuscript.

\section{Acknowledgments}

The authors wish to thank the KVB secretariat and the staff for their acceptance and assistance in accessing this data. 
Table-4: HD score grades of dogs of different breeds in a retrospective study on the canine HD scheme in Kenya.

\begin{tabular}{|c|c|c|c|c|c|c|c|c|c|c|}
\hline \multirow{2}{*}{$\begin{array}{l}\text { HD } \\
\text { score } \\
\text { grade }\end{array}$} & \multicolumn{9}{|c|}{ Breed } & \multirow[t]{2}{*}{ Total } \\
\hline & Boxer & Doberman & $\begin{array}{l}\text { Great } \\
\text { Dane }\end{array}$ & $\begin{array}{l}\text { Golden } \\
\text { Retriever }\end{array}$ & $\begin{array}{l}\text { German } \\
\text { Shepherd }\end{array}$ & $\begin{array}{c}\text { Hungarian } \\
\text { Vizla }\end{array}$ & $\begin{array}{l}\text { Labrador } \\
\text { Retriever }\end{array}$ & Rottweiler & $\begin{array}{l}\text { Rhodesian } \\
\text { Ridgeback }\end{array}$ & \\
\hline$>18$ & - & 1 & - & - & 77 & & 10 & 10 & - & 98 \\
\hline $13-18$ & - & - & 1 & 1 & 139 & 1 & 26 & 22 & 3 & 193 \\
\hline $9-12$ & 3 & 5 & 2 & - & 147 & - & 30 & 30 & 6 & 223 \\
\hline $7-8$ & - & 1 & - & - & 20 & - & 5 & 14 & 1 & 41 \\
\hline $4-6$ & - & 2 & - & - & 13 & - & 1 & 15 & 4 & 35 \\
\hline $1-3$ & - & - & - & - & - & - & - & 1 & - & 1 \\
\hline Total & 3 & 9 & 3 & 1 & 396 & 1 & 72 & 92 & 14 & 591 \\
\hline
\end{tabular}

$\mathrm{HD}=$ Hip dysplasia

\section{Competing Interests} interests.

The authors declare that they have no competing

\section{References}

1. Raghuvir, H.B., Shivrajsinh, K.J., Dipak, N.S., Harit, D.B., Chirag, A.B. and Naresh, H.K. (2013) Treatment of canine hip dysplasia: A review. J. Anim. Sci. Adv., 3(12): 589-597.

2. Dennis, R. (2012) Interpretation and use of BVA/KC hip scores in dogs. Practice, 34: 178-194.

3. Lust, G. (1997) An overview of the pathogenesis of canine hip dysplasia. J. Am. Vet. Med. Assoc., 210: 1443-1445.

4. Skurková, L. and Ledecký, V. (2009) Early diagnosis of canine hip dysplasia. Folia Vet., 53(2): 77-82.

5. Todhunter, R.J. and Lust, G. (2003) Hip dysplasia: Pathogenesis. In: Slatter, D., editor. Textbook of Small Animal Surgery. Saunders, Philadelphia. p2009-2019.

6. Flückiger, M. (2007) Scoring radiographs for canine hip dysplasia - The big three organisations in the world. Euro. J. Comp. Anim. Pract., 17(2): 135-140.

7. Guo, G., Zhou, Z., Wang, Y., Zhao, K., Zhu, L., Lust, G., Hunter, L., Friedenberg, S., Li, J., Zhang, Y., Harris, S., Jones, P., Sandler, J., Krotscheck, U., Todhunter, R. and Zhang, Z. (2011) Canine hip dysplasia is predictable by genotyping. Osteoarthritis Cartilage, 19: 420-429.

8. Sanchez-Molano, E., Pong-Wong, R., Clements, D.N., Blott, S.C., Wiener, P. and Woolliams, J.A. (2015) Genomic prediction of traits related to canine dysplasia. Front. Genet., 6: 97.

9. Coopman, F., Verhoeven, G., Paepe, D., van Bree, H., Duchateau, L. and Saunders, J.H. (2007) Inter observer agreement on the radiographic assessment of canine hip dysplasia. Vlaam. Diergeneeskd. Tijdschr., 76: 417-422.

10. Nouh, S.R., Hoyda, M.A., Haithem, A.F. and Mohamed, M.S. (2014) A retrospective study on canine hip dysplasia in different breeds in Egypt. Glob. Vet., 13(4): 503-510.

11. Ginja, M.M., Silvestre, A.M., Colaço, A.M., GonzaloOrden, J., Melo-Pinto, J.M., Orden, P., Llorens-Pena, M.A. and Ferreira, A.J. (2008) Hip dysplasia in Estrela mountain dogs - Prevalence and genetic trends 1991-2005. Vet. J., 46: 541-549.

12. Kaneene, J.B., Mostosky, U.V. and Miller, R. (2009) Update of a retrospective cohort study of changes in hip joint phenotype of dogs evaluated by the OFA in the United States, 1989-2003. Vet. Surg., 38: 398-405.

13. Anderson, A. (2011) Treatment of hip dysplasia. J. Small Anim. Pract., 52: 182-189.

14. Panigrahi, P.N. (2014) Conservative treatment of hip dysplasia in a Labrador dog - A case study. Vet. Res. Int., 2(4): 105-107.

15. Kirkby, A.K. and Lewis, D.D. (2009) Canine hip dysplasia: Reviewing the evidence for nonsurgical management. Vet. Surg., 41: 2-9.

16. Vezzoni, A., Boiocchi, S., Vezzoni, L., Vanelli, A.B. and Bronzo, V. (2010) Double pelvic osteotomy for the treatment of hip dysplasia in young dogs. Vet. Comp. Orthop. Traumatol., 23: 444-452.

17. Altunatmaz, K., Yucel, R., Devecioglu, Y., Saroglu, M. and Ozsoy, S. (2003) Treatment of canine hip dysplasia using triple pelvic osteotomy. Vet. Med. Czech, 48(1-2): 41-46.

18. Yaprakci, M.V., Marek, G. and Katarzyna, S. (2013) Clinical comparative evaluation of the V-cut pelvic ostectomy in the management of canine hip dysplasia. Bull. Vet. Inst. Pulawy, 57: 243-247.

19. Jensen, D.J. and Sertl, G.O. (1992) Sertl shelf arthroplasty in the treatment of canine hip dysplasia. Vet. Clin. North Am. Small Anim. Pract., 22: 683-701.

20. Oakes, M.G., Lewis, D.D., Elkins, A.D., Hosgood, G., Dial, S.M. and Oliver, J. (1996) Evaluation of shelf arthroplasty as a treatment for hip dysplasia in dogs. J. Am. Vet. Med. Assoc., 208: 1838-1845.

21. Katariina, M. (2004) Breeding Against Hip and Elbow Dysplasia in Dogs. Academic Dissertation, the Faculty of Agriculture and Forestry of the University of Helsinki.

22. Ginja, M.M.D., Silvestre, A.M., Gonzalo-Orden, J.M. and Ferreira, A.J.A. (2010) Diagnosis, genetic control and preventive management of canine hip dysplasia: A review. Vet. J., 184(3): 269-276.

23. Zhu, L., Zhang, Z. and Friedenberg, S. (2009) The long (and winding) road to gene discovery for canine hip dysplasia. Vet. J., 181(2): 97-110.

24. Chase, K., Lawler, D.F., Adler, F.R., Ostrander, E.A. and Lark, K.G. (2004) Bilaterally asymmetric effects of quantitative trait loci (QTLs): QTLs that affect laxity in the right versus left coxofemoral (hip) joints of the dog (Canis familiaris). Am. J. Med. Genet. A., 124(3): 239-247.

25. Ginja, M.M., Silvestre, A.M. and Ferreira, A.J. (2008) Passive hip laxity in Estrela mountain dog - Distraction index, heritability and breeding values. Acta Vet. Hung., 56(3): 303-312.

26. Manley, P.A., Adams, W.M., Danielson, K.C., Duel, R.T. and Linn, K.A. (2007) Long-term outcome of juvenile pubic symphysiodesis and triple pelvic osteotomy in dogs with hip dysplasia. J. Am. Vet. Med. Assoc., 230(2): 206-210.

27. Sallander, M.H., Hedhammar, A. and Trogen, M.E.H. (2006) Diet, exercise, and weight as risk factors in hip dysplasia and elbow arthrosis in Labrador retrievers. J. Nutr., 136: 2050S-2052S. 